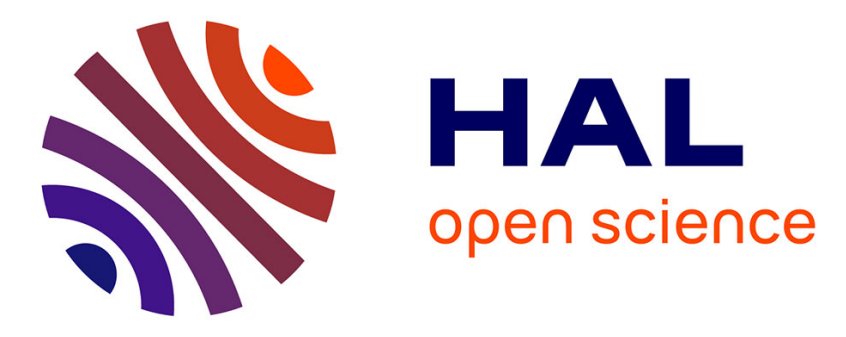

\title{
DNA damage and repair in a model of rat vascular injury
}

Amalia Forte, Mauro Finicelli, Mario Grossi, Mariano Vicchio, Nicola Alessio, Pasquale Santè, Marisa de Feo, Maurizio Cotrufo, Liberato Berrino, Francesco Rossi, et al.

\section{To cite this version:}

Amalia Forte, Mauro Finicelli, Mario Grossi, Mariano Vicchio, Nicola Alessio, et al.. DNA damage and repair in a model of rat vascular injury. Clinical Science, 2010, 118 (7), pp.473-485. 10.1042/CS20090416 . hal-00555005

\section{HAL Id: hal-00555005 https://hal.science/hal-00555005}

Submitted on 12 Jan 2011

HAL is a multi-disciplinary open access archive for the deposit and dissemination of scientific research documents, whether they are published or not. The documents may come from teaching and research institutions in France or abroad, or from public or private research centers.
L'archive ouverte pluridisciplinaire HAL, est destinée au dépôt et à la diffusion de documents scientifiques de niveau recherche, publiés ou non, émanant des établissements d'enseignement et de recherche français ou étrangers, des laboratoires publics ou privés. 


\section{DNA DAMAGE AND REPAIR IN A MODEL OF RAT VASCULAR INJURY}

${ }^{* 1}$ Amalia Forte, ${ }^{1}$ Mauro Finicelli, ${ }^{1}$ Mario Grossi, ${ }^{2}$ Mariano Vicchio, ${ }^{1}$ Nicola Alessio, ${ }^{2}$ Pasquale Santè, ${ }^{2}$ Marisa De Feo, ${ }^{2}$ Maurizio Cotrufo, ${ }^{1}$ Liberato Berrino, ${ }^{1}$ Francesco Rossi, ${ }^{1}$ Umberto Galderisi, ${ }^{1}$ Marilena Cipollaro

Departments of ${ }^{1}$ Experimental Medicine and ${ }^{2}$ Cardiothoracic and Respiratory Sciences, Second University of Naples, Italy

\section{"Correspondence to:}

Amalia Forte

Department of Experimental Medicine, Section of Biotechnology and Molecular Biology

Second University of Naples,

Via L. De Crecchio, 7 - 80138 Naples, Italy

E-mail: amalia.forte@unina2.it

Phone: $++39-081-5665930$

Fax: $\quad++39-081-5667547$

Key words: restenosis, negative remodeling, DNA repair, phospho-H2A.X, 8-oxo-dG, oxidative stress

Running title: DNA damage and repair after vascular injury 


\section{ABSTRACT}

Restenosis rate following vascular interventions still limits their long-term success. Oxidative stress plays a relevant role in this pathophysiological phenomenon, but less attention has been devoted to its effects on DNA damage and to the subsequent mechanisms of repair.

We analysed in a model of arteriotomy-induced stenosis in rat carotids the time-dependent expression of DNA damage markers and of DNA repair genes, together with the assessment of proliferation and apoptosis indexes.

The expression of the oxidative DNA damage marker 7,8-dihydro-8-oxo-2'-deoxyguanosine was increased at 3 and 7 days after arteriotomy, with immunostaining distributed in the injured vascular wall and in perivascular tissue. The expression of the DNA damage marker phospho-H2A.X was less relevant but increasing from $4 \mathrm{hrs}$ to 7 days after arteriotomy, with immunostaining prevalently present in the adventitia and, to a lesser extent, in medial smooth muscle cells at the injury site.

RT-PCR indicated a decrease of 8 out of 12 genes of the DNA repair machinery we selected from 4 hrs to 7 days after arteriotomy with the exception of increased Muyth and Slk genes $(p<0.05)$.

Western Blot revealed a decrease of $\mathrm{p} 53$ and catalase at 3 days after arteriotomy $(\mathrm{p}<0.05)$.

A maximal $7 \%$ of BrdU-positive cells in endothelium and media occurred at 7 days after arteriotomy, while the apoptotic index peaked at 3 days after injury $(\mathrm{p}<0.05)$.

Our results highlight a persistent DNA damage presumably related to a temporary decreased expression of the DNA repair machinery and of the antioxidant enzyme catalase, playing a role in stenosis progression. 


\section{INTRODUCTION}

The present strategies for severe atherosclerosis in arteries rely on angioplasty procedures, directional coronary atherectomy and bypass surgery. In reference to the occlusion of extra-cardiac arteries, carotid artery can be submitted to endarterectomy or to angioplasty to normalize impaired cerebral hemodynamics. Recent randomized trials did not reveal so far a substantial advantage of the more recently introduced carotid stenting with respect to endarterectomy, that remains a primary choice for treatment of severe symptomatic carotid stenosis [1].

Restenosis is considered as an excessive reparative reaction to vascular injury occurring during the above mentioned revascularization procedures. The rate of this pathophysiological phenomenon is still high in the Western Countries [2].

Main actors in restenosis progression are cell proliferation and migration, neointima formation, cell transdifferentiation, inward remodelling and the related impaired extracellular matrix (ECM) metabolism. Also the intraoperative damage to adventitia and to vasa vasorum and nervous fibers it contains can have deleterious effects on restenosis [3], as vascular injury can stimulate the shift of adventitial fibroblasts to activated myofibroblasts (MFs) [4], that in turn can exacerbate vessel remodeling and contribute to neointima formation after vascular injury.

The in-depth knowledge of the different cell types and of the molecular pathways contributing to restenosis could lead to establish novel protocols for therapy of restenosis.

Reactive oxygen species (ROS) include a number of oxygen-derived molecules that act as rapidly diffusing, short-lived messenger molecules, with a recognized role in signal transduction. ROS can be generated by a number of different enzymes, including NAD(P)H oxidases, whose activity is counterbalanced by other molecules, such as glutathione, superoxide dismutases (SOD), calatalase (CAT) and peroxidases, in order to preserve the cellular redox balance [5]. ROS can induce a potential damage of cellular elements. The level of ROS in the vascular wall can be increased by different stimuli, including shear stress [6], inflammation and growth signals. For example, Angiotensin II is a potent activator of $\mathrm{NAD}(\mathrm{P}) \mathrm{H}$ oxidase in the cardiovascular system, able to increase the production of ROS [7].

ROS have been implicated in hypertension and in other vascular diseases, as the intracellular signaling cascades stimulated by ROS play an important role in their pathogenesis. Free radicals do not contribute to diseases solely as random damaging agents, but can serve as signaling molecules and modify at different levels transcription factors and thus have a direct role in transcriptional regulation [8]. ROS-induced stimulation of protein phosphorylation pathways modulates transcription factor activities and gene expression, which results in a variety of responses such as cell growth, differentiation, or apoptosis $[9,10]$. The particular response observed depends on the cell type and the concentration and duration of ROS production. ROS production has been detected in vascular smooth muscle cells (SMCs) and endothelial cells (ECs) at the injury site, but it may also derive from infiltrating leukocytes.

Although the general cytotoxic effects of ROS in cardiovascular diseases has been well assessed [11], with particular relevance to atherosclerosis and to myocardial infarction, only a few studies specifically addressed the molecular events related to DNA damage and repair in restenosis.

In this study we aimed to analyse in a well characterized model of rat carotid arteriotomy the time course of two robust markers of DNA damage and repair, the 7,8-dihydro-8-oxo-2'-deoxyguanosine (8-oxo-dG) and the phosphorylation of the H2A.X histone isoform (phospho-H2A.X), together with the determination of the apoptosis and proliferation indexes, the Western Blot analysis of Mn-SOD, catalase and p53, known involved in ROS metabolism, DNA repair and apoptosis, and with the RTPCR expression profile of a panel of 12 DNA repair-related genes.

Overall data highlight a marked and persistent oxidative damage of DNA parallel to cell proliferation and apoptosis, and relevant differences in the expression profiles of genes involved in the DNA repair machinery, possibly reflecting distinct roles for these factors in the molecular events following arterial surgical injury. 


\section{METHODS \\ Animals}

Studies were carried out on 12 week-old male Wistar rats (230-250 g) (Charles Rivers, France). All animals were handled in compliance with the 'Guide for the Care and Use of Laboratory Animals' published by the US National Institute of Health (NIH publication No. 85-23, revised 1996). All protocols were approved by the Animal Care and Use Committee of the Second University of Naples. Rats were acclimatized and quarantined for at least one week before undergoing surgery,

\section{Vascular Injury}

Arteriotomy of rat common carotid artery was performed as already published [12]. Briefly, a plastic Scanlom clamp for coronary artery grafting was placed for 10 seconds on the carotid causing a crushing lesion to the vessel. At the same point where the clamp was applied, a $0.5 \mathrm{~mm}$ longitudinal incision was done on the full thickness of the carotid. The incision did not cross to the other side of the vessel. Haemostasis was obtained with a single adventitial 8.0-gauge polypropylene stitch. Once bleeding stopped, the carotid artery was carefully examined and blood pulsation was checked distally to the incision.

\section{RNA extraction and RT-PCR analysis}

Total RNA was extracted from injured rat carotids at $4 \mathrm{hrs}$ and at 3 and 7 days after arteriotomy $(n=4$ rats, for each time point) and from uninjured rat carotids $(n=4)$ using the RNAeasy minikit (Qiagen) according to manufacturer's instructions. RNA was treated with DNase (Qiagen) to remove DNA contamination. RNA concentration was measured using a NanoDrop ND-1000 spectrophotometer (NanoDrop Technologies). RNA integrity was verified by electrophoresis on denaturing $1 \%$ agarose gel. Absence of residual DNA was verified by PCR on total RNA without reverse transcription.

cDNA was generated from $200 \mathrm{ng}$ of each RNA sample. Reverse transcription was done at $42^{\circ} \mathrm{C}$ for $1 \mathrm{hr}$ in presence of random examers and Moloney-Murine Leukemia Virus (M-MULV) reverse transcriptase (Finnzymes). GeneBank sequences for rat mRNAs and the Primer Express software (Applied Biosystem) were used to design primer pairs for the genes related to DNA repair listed in Table 1. Expression data were normalized with respect to the level of the house keeping gene GAPDH.

Primer pairs were chosen to yield 100-150 bp PCR products and were validated running the PCR products on agarose gel to confirm a single band. $65^{\circ} \mathrm{C}-94^{\circ} \mathrm{C}$ melting curves were also generated to determine whether there were any spurious amplification products. Each RT-PCR reaction was repeated at least three times. The real-time PCR assays were run on an Opticon 4 machine (BioRad). Reactions were performed in quadruplicate according to the manufacturer's instructions using the SYBR Green PCR master mix (Stratagene). Relative quantitative RT-PCR was used to determine the fold difference for gene expression in comparison to basal levels in carotids from uninjured rats. The real time PCR efficiency was calculated for each primer pair using a dilution series and the MJ Opticon II analysis software.

Real Time PCR results were verified also by semi-quantitative RT-PCR using the ChemiDoc associated software Quantity One (Bio-Rad) for densitometric analysis of PCR products after electrophoresis.

\section{Western blotting}

Rat carotid segments were harvested 3 and 7 days after arteriotomy ( $\mathrm{n}=3$ for each group) and from uninjured rats $(n=3)$. Single carotids were rinsed thoroughly with cold phosphate-buffered saline to remove blood components and frozen immediately in liquid nitrogen. The frozen tissue was disrupted and lysed in a buffer containing $50 \mathrm{mM}$ Tris- $\mathrm{HCl}$ pH 7.4, $250 \mathrm{mM} \mathrm{NaCl}, 0.1 \%$ Triton X-100 and a protease inhibitor cocktail (Roche). 
The lysates were then centrifuged for 10 minutes at $10,000 \mathrm{~g}$ at $4^{\circ} \mathrm{C}$. Protein concentration in the supernatants was assessed using the Bradford assay. $20 \mu \mathrm{g}$ of each sample was loaded, electrophoresed in a polyacrylamide gel and electroblotted onto a nitrocellulose membrane.

Primary antibodies to detect catalase (Cell Signaling, monoclonal anti-mouse, dil. 1:2000), MnSOD (Upstate, polyclonal anti-rabbit, dil. 1:1000), p53 (Santa Cruz, monoclonal anti-mouse, dil. 1:500), and $\alpha$-tubulin (Santa Cruz, monoclonal anti-mouse, dil. 1:500), were incubated overnight at $4^{\circ} \mathrm{C}$. All the antibodies were used according to the manufacturers' instructions. Immunoreactive signals were detected with a horseradish peroxidase-conjugated secondary antibody (Santa Cruz) and reacted with SuperSignal WestPico or WestFemto (Pierce). Signal acquisition quantitative analysis and normalization with respect to $\alpha$-tubulin were done through the ChemiDoc associated software Quantity One.

\section{Histological analysis}

Carotid arteries were harvested at 4 hrs, 3 days and 7 days after arteriotomy for morphological and immunohistochemical analysis. Harvested vessels were fixed in $4 \%$ buffered formaldehyde, dehydrated and embedded in paraffin. For each injured carotid, at least sixty serial cross-sections were observed under a light microscope at 20x magnification; image screening and photography were performed using a Leica IM 1000 System. The carotid cross-sections at the injury site showing maximal remodeling and proliferative phenomena were identified and further analysed.

$5 \mu \mathrm{m}$ cross-sections were stained with hematoxylin-orcein for nucleus and elastic fiber staining, respectively. Image screening and photography of serial cross-sections submitted to colorimetric immunohistochemical analysis were performed using a Leica IM1000 System. Image screening and photography of serial cross-sections submitted to fluorescence immunohistochemical analysis were performed using the Leica $4000 \mathrm{~F}$ software. We considered for quantitative analysis after all immunohistochemistry experiments only positive cells located in the endothelium and in the tunica media, as the adventitia was difficult to be distinguished from perivascular tissue in injured carotids and could have been partially damaged during carotid harvesting or histological processing.

\section{8-oxo-dG immunohistochemical detection}

Immunohistochemistry was performed on carotid arteries taken at 3 and 7 days after arteriotomy, on abdominal aorta taken from rats at 3 days after carotid arteriotomy and on control carotids taken from uninjured rats immediately after anaesthesia ( $n=4$ for each group). The $4 \%$ formaldehydefixed carotid cross-sections $(5 \mu \mathrm{m})$ were deparaffinised, rehydrated and treated with Proteinase $\mathrm{K}$ (Roche) for $15^{\prime}$ at $37^{\circ} \mathrm{C}$. After washing, sections were treated with $100 \mu \mathrm{g} / \mathrm{ml}$ RNase A (Fermentas) for $1 \mathrm{hr}$ at $37^{\circ} \mathrm{C}$ to increase sensitivity and specificity for DNA oxidation. DNA was then denatured with $2 \mathrm{~N} \mathrm{HCl}$ for 5 ' at RT. After neutralization, the sections were incubated in blocking solution containing $10 \%$ goat serum for $1 \mathrm{hr}$ at $\mathrm{RT}$ and then with the primary antibody for 8-oxo-dG (Trevigen, monoclonal anti-mouse, dil. 1:250) o.n. at $4^{\circ} \mathrm{C}$. After washing, sections were incubated with FITC-conjugated secondary antibody (Jackson ImmunoResearch, anti-mouse, dil. 1:100) for 1 $\mathrm{hr}$ at RT. After washing, DNA was stained with fluorescent dye Hoechst 33258 (Sigma-Aldrich) for nuclear identification. Specimen image screening and photography were performed using a Leica F4000 System. Five cross-sections localised at the injury site were analysed for each carotid. The percentages of 8-oxo-dG positive nuclei in the tunicae intima and media were calculated by determining the number of Hoechst-stained nuclei positive for 8-oxo-dG staining.

\section{H2A.X immunohistochemical detection}

Immunohistochemistry were performed on carotid arteries taken at $4 \mathrm{hrs}, 3$ days and 7 days after arteriotomy and on carotids from uninjured rats ( $\mathrm{n}=4$ for each group). The $4 \%$ formaldehyde-fixed carotid cross-sections $(5 \mu \mathrm{m})$ were deparaffinised and rehydrated. Antigen retrieval was done in microwave through incubation in $10 \mathrm{mM}$ Citrate buffer $\mathrm{pH}$ 6. Endogenous peroxidases were blocked 
with $4 \% \mathrm{H}_{2} \mathrm{O}_{2}$. Blocking was done in $5 \%$ donkey serum, followed by incubation with the primary antibody for phospho-H2A.X (Cell Signaling, polyclonal anti-rabbit, dil. 1:50) at $4{ }^{\circ} \mathrm{C}$ o.n. After washing, slides were incubated with biotin-conjugated secondary antibody (Santa Cruz, dil. 1:200). Staining was done through incubation with peroxidase-streptoavidin (Vector Laboratories) for 30' at RT, followed by incubation with 3,3'-diaminobenzidine (Vector Laboratories). Nuclei were counterstained with Mayer's hematoxylin (Sigma-Aldrich). Image screening and photography of serial cross-sections submitted to colorimetric immunohistochemical analysis were performed using a Leica IM1000 System.

\section{BrdU proliferation assay}

Rats were submitted to carotid arteriotomy and $18 \mathrm{hrs}$ prior to sacrifice at 3 and 7 days after injury they were administered i.p. with $50 \mathrm{mg} / \mathrm{kg}$ Bromodeoxyuridine (BrdU) (Roche) for detection and quantification of cells that entered into the cell cycle within $24 \mathrm{hrs}$ of sacrifice.

Endogenous peroxidases were blocked with $4 \% \mathrm{H}_{2} \mathrm{O}_{2}$. DNA was then denatured with $2 \mathrm{~N} \mathrm{HCl}$ for 1 $\mathrm{hr}$ at $37^{\circ} \mathrm{C}$. After neutralization with $100 \mathrm{mM}$ sodium borate $\mathrm{pH} 8.5$, the sections were incubated with $01 \%$ tripsin for $20^{\prime}$ at $37^{\circ} \mathrm{C}$. After washing, slides were incubated with primary antibody antiBrdU (Roche, monoclonal anti-mouse, $6 \mu \mathrm{g} / \mathrm{ml}$ ) for $1 \mathrm{hr}$ at RT.

After washing, slides were incubated with biotin-conjugated secondary antibody (Santa Cruz, dil. 1:100). Staining was done through incubation with peroxidase-streptoavidin (Vector Laboratories) for 30' at RT, followed by incubation with 3,3'-diaminobenzidine (Vector Laboratories). Nuclei were counterstained with Mayer's hematoxylin. Image screening and photography of serial crosssections submitted to colorimetric immunohistochemical analysis were performed using a Leica IM1000 System.

Five cross-sections localised at the injury site were analysed for each carotid. The percentages of BrdU-positive nuclei in the tunicae intima and media were calculated by determining the number of hematoxylin-stained nuclei in the tunicae intima and media positive for immunohistochemical staining of BrdU.

\section{TUNEL assay}

Assays were performed on carotid arteries taken at 3 and 7 days after arteriotomy and on control carotids taken from uninjured rats after anaesthesia ( $\mathrm{n}=4$ for each group). The $4 \%$ formaldehydefixed sections $(5 \mu \mathrm{m})$ were deparaffinised and rehydrated. The tissue was permeabilized with 20 $\mu \mathrm{g} / \mathrm{ml}$ Proteinase K (Roche) for 30 minutes. After washing, Terminal deoxynucleotidyl Transferase (TdT) enzyme and TMR red-labeled nucleotides were added to the tissue sections according to the manufacturer's specifications (Roche). After 3'OH end-labeling for $1 \mathrm{~h}$ at $37^{\circ} \mathrm{C}$, the sections were washed in PBS and nuclei were counterstained with Hoechst 33258 (Sigma-Aldrich). Specimen image screening and photography were performed using a Leica F4000 System. Five cross-sections localised at the injury site were analysed for each carotid. The percentages of apoptotic nuclei in the tunicae intima and media were calculated by determining the number of Hoechst-stained nuclei positive for TUNEL staining. When observed with 40-100x objectives, cells showing morphological features typically associated with apoptosis, as well as positive to TUNEL reaction, were considered to be apoptotic. A number of randomly selected slides were quantified for TUNEL staining by two independent observers to assess inter-observer variation.

\section{Statistical analysis}

All statistical analysis was performed using GraphPad software (Prism 4.0). Data are presented as the mean \pm SEM. Statistical significance was determined using two-way analysis of variance followed by Bonferroni's multiple comparison test. Values of $p<0.05$ were considered significant. 


\section{RESULTS}

Carotid arteriotomy induces DNA damage at the injury site:

Rat carotids have been harvested at 3 and 7 days after arteriotomy and from uninjured rats $(\mathrm{n}=5$ for each group) and the cross sections at the injury site were submitted to immunohistochemistry for 8oxo-dG, a marker of nucleic acid oxidative damage, and for phosphorylated form of histone H2A.X, a marker for DNA double strand break (DSBs).

$15.5 \%$ and $24 \%$ of nuclei in the endothelium and in the tunica media were positive for 8 -oxo-dG staining at 3 and 7 days after arteriotomy, respectively $(\mathrm{p}<0.05)$ (Fig. 1, upper panel). The nuclei positive for oxidative DNA damage were homogeneously distributed in all the three tunica layers and in the perivascular tissue, around the injury site and the polypropylene stitch applied as suture (Fig. 1, lower panel). Some positive cells were also detected in contralateral uninjured carotids and in abdominal aorta in rats sacrificed at 3 and 7 days after arteriotomy (data not shown), thus indicating a systemic oxidative stress of the vasculature. A basal level of about $1.5 \%$ cells positive to 8-oxo-dG has been detected in carotids from healthy uninjured rats (Fig. 1).

It is well known that ROS can induce also RNA oxidative damage in cells. The hybridisation signal we detected for 8-oxo-dG was specific for nuclear DNA, as the carotid cross-sections were treated with ribonuclease during the experimental procedure.

Immunohistochemical analysis of phospho-H2A.X revealed increasing positive cells in injured carotids ranging from $4 \mathrm{hrs}$ to 7 days after arteriotomy (Fig. 2 B-D). Since the immunostaining for phospho-H2A.X was localized mainly in the adventitia and in perivascular tissue, we did not report the percentage of positive nuclei for this DNA damage marker but only report a qualitative analysis. Of interest, phospho-H2A.X-positive cells were mainly localised at the injury site, while cells positive for 8-oxo-dG staining were distributed along all the circumference of the injured carotids. Rare cells positive for phospho-H2A.X immunostaining have been detected in carotids from healthy uninjured rats (Fig. 2 A).

\section{Carotid arteriotomy induces transient apoptosis at the injury site:}

Rat carotids have been harvested at 3 and 7 days after arteriotomy and from uninjured rats ( $\mathrm{n}=5$ for each group) and the cross sections at the injury site were submitted to TUNEL assay for apoptosis detection. Our results reveal a $13.3 \%$ of TUNEL-positive cells at 3 days after arteriotomy $(p<0.05)$, followed by a decrease to $8.9 \%$ of TUNEL-positive cells at 7 days after arteriotomy $(p<0.05)$ (Fig. 1, upper panel). Apoptotic cells were located mainly in the endothelium and in the adventitia, around the injury site (Fig. 1, lower panel). Carotids from uninjured rats showed a basal level of only $0.7 \%$ of TUNEL-positive cells (Fig, 1).

\section{Carotid arteriotomy induces cell proliferation in the three tunica layers:}

Rat carotids have been harvested at 3 and 7 days after arteriotomy and from uninjured rats ( $\mathrm{n}=5$ for each group) and the cross sections at the injury site were submitted to BrdU immunohistochemical detection for assessment of cell proliferation index.

Our results reveal a $4.4 \%$ of BrdU-positive cells at 3 days after arterioyomy $(\mathrm{p}<0.05)$, followed by an increase to $7 \%$ of BrdU-positive cells at 7 days after arteriotomy ( $\mathrm{p}<0.05)$ (Fig. 1, upper panel). BrdU-positive cells were undetectable in carotids from healthy uninjured rats.

We revealed the presence of BrdU positive cells both in the endothelium and in the tunica media, as well as in focal neointima, when present (Fig, 1, lower panel).

We highlighted BrdU positive cells also in the adventitia and in perivascular tissue. In particular, we revealed the presence of actively forming vasa vasorum in the adventitia at 7 days after arteriotomy (Fig. 1, lower panel, C, 40x magnification image).

\section{Carotid arteriotomy affects the expression profiles of proteins involved in ROS metabolism and DNA repair/apoptosis:}

Rat carotids have been harvested at 3 and 7 days after arteriotomy and from uninjured rats ( $\mathrm{n}=3$ for each group) and protein lysates have been used for determination of the expression level of p53, $\mathrm{Mn}-\mathrm{SOD}$ and catalase. 
Western blot analysis revealed a significant 2.6-fold decrease of catalase at 3 days after arteriotomy $(\mathrm{p}=0.02)$ followed by a return to basal levels at 7 days after arteriotomy (Fig. 3). Conversely, we did not find any significant variation of Mn-SOD after arteriotomy (Fig. 3).

Finally, $\mathrm{p} 53$ showed a significant 1.61 decrease at 3 days after arteriotomy $(\mathrm{p}=0.04)$, followed by an increase at 7 days after vascular injury (Fig. 3), but not statistically significant in comparison to levels detected in carotids from uninjured rats, due to high variability among rats. We also analysed by Western Blot the expression level of ATM, responsible for H2A.X phosphorylation and of acetylated and phosphorylated isoforms of p53 in injured carotids in comparison to uninjured carotids, but unfortunately we were unable to detect any signal, with the exception of a very faint band corresponding to acetylated p53 detectable only at 7 days after arteriotomy (data not shown). This was probably due to the very low level of expression of these proteins and to the small amount of proteins that can be extracted from the small fragments of injured rat carotids.

\section{Carotid arteriotomy differentially affects the expression profiles of DNA repair-related genes:}

Rat carotids have been harvested at 4 hrs and at 3 and 7 days after arteriotomy and from uninjured rats ( $\mathrm{n}=4$ for each group) and total RNAs have been used for determination by RT-PCR of the expression level of 12 DNA repair-related genes belonging to four distinct classes according to their mechanism of action: 1) Double Strand Break (DSB) (genes analysed: Brca2, Mre11a, Xrcc4); 2) Mismatch Excision Repair (MER) (genes analysed: Mlh1, Prkdc, Pold3); 3) Base Excision Repair (BER) (genes analysed: Mutyh, Ogg1, Parp1); 4) Nucleotide Excision Repair (NER) (genes analysed: Nthl1, Rad23a, Slk). The characteristics of primers pairs used for RT-PCR and the function of gene products are listed in Table 1.

RT-PCR analysis revealed a decrease of the expression at mRNA level of 8 out of 12 genes we selected, with only two increased mRNAs (Mutyh and Slk) and two genes whose mRNA level was unaffected by arteriotomy (Parp1 and Pold3).

In more detail, for what concerns genes playing a role in DSB repair, we revealed that Brca2 mRNA was expressed in uninjured carotids, but was undetectable at $4 \mathrm{hrs}$ after injury, then turning back to basal levels at 3 and 7 days after injury. Mre1la mRNA showed a transient significant 1.8fold decrease at $4 \mathrm{hrs}$ and 3 days after arteriotomy ( $\mathrm{p}=0.04)$, while Xrcc 4 down-regulation of expression of 2.7-fold was delayed at 3 and 7 days after carotid injury ( $\mathrm{p}=0.01$ ) (Fig. 4).

A similar behaviour was detected for the mRNA expressed by selected genes involved in MER, as Mlh1 was expressed in uninjured carotids, but was undetectable at $4 \mathrm{hrs}$ after injury, then turning back to basal levels at 3 and 7 days after injury, while Prkdc showed a maximal 1.85-fold decrease at $4 \mathrm{hrs}$ after arteriotomy $(\mathrm{p}=0.04)$, then turning back to basal levels at 7 days after injury. Pold3 mRNA level was unaffected by carotid arteriotomy (Fig. 4).

For what concerns genes involved in BER, Mutyh mRNA was undetectable both in carotids from uninjured rats and at $4 \mathrm{hrs}$ after arteriotomy, while it was markedly and persistently expressed at 3 and 7 days after injury. This expression profile was counterbalanced by the levels of Ogg1 mRNA, showing a temporary 2.5 -fold decrease at 4 hrs after arteriotomy $(\mathrm{p}=0.04)$. Parp 1 mRNA level was unaffected by carotid arteriotomy (Fig. 4).

Finally, for what concerns genes included in the NER category, Nthll mRNA was expressed in uninjured carotids, but was undetectable at $4 \mathrm{hrs}$ after injury, then turning back to basal levels at 3 and 7 days after injury, while Rad23 showed a 2.4-fold decrease at 3 and 7 days after arteriotomy $(\mathrm{p}=0.004$ and $\mathrm{p}=0.04$, respectively). Slk showed a partially different expression profile, since its mRNA exhibited a temporary 1.8 -fold increase at $4 \mathrm{hrs}$ after arteriotomy $(\mathrm{p}=0.01)$, followed by a persistent 1.85 -fold decrease both at 3 and 7 days after arteriotomy ( $\mathrm{p}=0.04$ ) (Fig. 4). 


\section{DISCUSSION}

Arteriotomy induces the accumulation of DNA damage markers in injured carotids:

Experimental vascular surgical injury remains a major tool to dissect the molecular pathways involved in stenosis progression and to identify novel potential targets for (re)stenosis limitation. The pathophysiological mechanisms induced by angioplasty and by arteriotomy can be different, and a model of surgical injury could be helpful in this concern. Consequently, we set up and validated an arteriotomy model of injury of rat common carotid [12] that mimics the injury affecting the arteries submitted to grafting or endarterectomy, since it is characterized by an interruption of the internal and external elastic lamina, which is considered clinically relevant for the development of arterial stenosis.

ROS formation and elimination, under physiological conditions, are well balanced. Enhanced activity of oxidant enzymes and/or reduced activity of antioxidant enzymes lead to the pathologic state of oxidative stress. A previous transcriptome analysis highlighted the activation of genes involved in inflammation and ROS production in the arteriotomy model of injury [13]. On the basis of these results, we decided to further analyze the pathways involved in DNA damage and repair, as these phenomena have been well investigated in atherosclerosis and in myocardial infarction, but only to a lesser extent in restenosis. The data concerning the expression of markers of DNA oxidative damage we obtained in this study are in agreement with our previous transcriptome analysis in the same model of injury [13]. We hypothesize that ROS production is increased not only by the inflammation triggered by vascular injury (namely the infiltration of monocytes and neutrophils in the injured vascular wall), but also by short-term systemic alterations of haemodynamic forces, then mechanotransduced in vascular cells and leading to the endothelial dysfunction.

8-oxo-dG is one of the most frequent base lesions accumulating after oxidative damage to DNA, due to the low redox potential of guanine, that makes this base particularly vulnerable [14]. Oxidized guanine pairs with adenine during DNA replication, inducing G:C to T:A transversions and it is repaired primarily through the DNA BER pathway.

phospho-H2A.X is another well known marker of DNA damage, and in particular of DSBs, When DSBs occur, they are always followed by the phosphorylation of the histone H2A.X, one of the most conserved variants of the H2A protein family [15]. H2A.X is phosphorylated at Serine 139 by kinases such as ataxia telangiectasia mutated (ATM) and ATM-Rad3-related (ATR) in the PI3K pathway. This newly phosphorylated protein, gamma/phospho-H2A.X, is the first step in recruiting and localizing DNA repair proteins [16].

The persistent high number of 8-oxo-dG- and phospho-H2A.X-positive cells we detected in arteriotomy-injured carotids and in perivascular tissue possibly reflects the relevant oxidative stress induced, either directly and indirectly, by arteriotomy, together with the lack of an effective repair of DNA damage, leading to apoptosis and to cell proliferation, as demonstrated by the TUNEL assay and the BrdU-labeling, respectively (Figg. 1, 2). The immunohistochemical data for 8-oxo-dG is supported by the RT-PCR analysis of the gene 8-oxoguanine DNA glycosylase (Ogg1) involved in DNA BER, that shows a significant decrease at $4 \mathrm{hrs}$ after arteriotomy, and that is counterbalanced by the activation of the expression of Mutyh at 3 and 7 days after injury (Fig. 4). The increase of 8-oxo-dG has been also highlighted in balloon-injured rat carotids [17].

The presence of phospho-H2A.X in cells in the adventitia and in perivascular tissue, and to a lesser extent, in the tunica media, in carotids harvested since 4 after arteriotomy (Fig. 2) is in agreement with data indicating phopsho-H2A.X as a very early marker of DNA DSBs and indicates the prolonged persistence after arteriotomy of DSBs, in agreement with the decreased expression of all the three DSB repair genes we examined by RT-PCR (Fig. 4), and possibly indicating a failure of the DSB repair machinery in steps subsequent the phosphorylation of H2A.X.

It has been hypothesized that perivascular inflammatory cells recruited after vascular injury play a role in the recruitment and/or proliferation of adventitial MFs, possibly through the release of ROS and/or cytokines, and thus contribute to vascular remodeling associated with restenosis [18]. 
The presence of phospho-H2A.X and of 8-oxo-dG has been detected also in atherosclerotic plaques of patients with coronary artery disease and in animal models, suggesting that DNA repair is inefficient also in this pathological status $[19,20]$.

Overall immunohistochemical data indicate that the DNA oxidative damage, supported by the presence of 8-oxo-dG, is predominant, in reference to the number of positive cells, in comparison to DNA DSB, supported by the presence of phospho-H2A.X (Figg. 1, 2). Moreover, our data highlight also a different distribution of 8-oxo-dG- and phospho-H2A.X-positive cells, with 8-oxo-dGpositive cells homogenously distributed in all the three tunica layers of injured carotids and phospho-H2A.X-positive cells present mainly in the adventitia around the injury site and, to a lesser extent, in the media and in neointima, when present.

\section{Arteriotomy induces cell proliferation and apoptosis in injured carotids:}

Arteriotomy induces a proliferative reparative reaction of the vascular wall, together with cell migration and the ECM synthesis.

Our data highlight an increased number of proliferating cells ranging from 3 to 7 days after arteriotomy (Fig. 1). The percentage of proliferating cells assessed through the BrdU-labeling in animal models of vascular injury is quite variable, depending on the kind of injury, on the target vessel and on the timing of the analysis. A direct comparison of the proliferation index in the arteriotomy model with data obtained in angioplasty models could be not correct, as the arteriotomy model of injury we applied induces a stenosis mainly related to a marked inward remodeling and to formation of neoadventitia, rather than to neointima, as commonly observed after angioplasty [12]. DNA damage is known to block cell cycle to allow the repair of DNA molecules. Our data show that arteriotomy induces both DNA damage and cell proliferation, possibly indicating a failure of mechanisms leading to growth arrest (e.g. through p21, GADD45, p16, p53).

Apoptosis is an essential component of normal development as well as of most developmental abnormalities and diseases. SMC and EC apoptosis occurs after vessel injury, in remodeling and in advanced atherosclerotic lesions. Apoptosis induced by exacerbated oxidative stress prevalent under pathophysiological conditions such as surgically-induced stenosis may profoundly affect this vascular disease. It usually occurs within a few hours or days after injury, mainly in the media and/or in the neointima, depending on the kind of injury and on the presence of atherosclerotic lesions. Vasoactive substances, such as nitric oxide, Angiotensin II and Endothelin-1 that are often altered in injured vessels, are among the regulators of apoptosis [21].

It is well known that apoptosis is stimulated by balloon angioplasty [22] and that the degree of cell loss is directly proportional to the intensity of the injury [23]. Apoptosis and proliferation are intimately coupled. The timing and level of cell apoptosis after vascular injury has been investigated through TUNEL assay in many different animal models and vessels, generating a large amount of heterogeneous data. For example, $70 \%$ of apoptotic nuclei have been detected in carotid media 30 min after angioplasty in rat [24]. Other studies revealed that apoptosis occurs in neointima from 7 to 30 days after angioplasty [25]. Furthermore, some authors clearly demonstrated the relevant influence of the kind of vascular trauma both on apoptosis and cell proliferation [26]. This last observation implies that our TUNEL data can be only partially compared to other published data, since our surgical injury model applied on rat carotid is radically different from angioplasty and could induce a different apoptotic reaction. In addition, we cannot exclude that necrotic cell death could also occur in arteriotomy-injured vessels, as hypothesized in other models of deep vascular injury [27]. Lastly, we successfully detected apoptotic nuclei also in the carotid intima (Fig. 1, lower panel), while investigations based on balloon angioplasty were not able to report the amount of TUNEL-positive nuclei in this layer, since it is damaged and removed by the balloon.

An efficient DNA repair can prevent or reduce accumulated DNA damage, thus preventing apoptosis. Consequently, the data suggesting a failure of the DNA repair machinery can be related, at least in part, to the apoptosis we highlighted after arteriotomy. The higher apoptotic index we detected at 3 days after arteriotomy could appear in contrast with the contemporary decrease of p53 (Fig. 3). Nonetheless, it has been demonstrated that p53-mediated apoptosis can occur without de 
novo RNA and protein synthesis in some cell types. Moreover, it has been suggested that endogenous p53 can exert an anti-apoptotic action, probably related to its DNA repair activity [28]. DNA damage can induce cell apoptosis, and thus be directly related to the apoptotic index we reported. In this concern, it has been recently demonstrated that the presence of 8-oxo-dG in cells can activate cell death [29]. But it should be also mentioned that the accumulation of phosphoH2A.X-positive cells could be a direct marker not only of DNA damage, but also of initial apoptosis, as it has been recently demonstrated that H2A.X is phosphorylated during apoptotic DNA fragmentation [30, 31].

\section{Arteriotomy induces a transient down-regulation of $p 53$ and catalase proteins:}

The tumor suppressor gene p53 encodes a transcription factor that activates genes involved in growth arrest and apoptosis. It has been demonstrated that adenoviral expression of p53 reduces cell proliferation in the rat carotid artery [32] or migration in the human saphenous vein [33] and conversely, antisense oligonucleotides to p53 increase proliferation [34].

An increased expression and phosphorylation of p53 has been associated with markers of DNA damage and activation of DNA repair pathways, suggesting that p53 expression is ultimately triggered by DNA damage to vessel-wall cells [20]. p53 can also catalyze by itself the repair of many forms of DNA damage $[35,36]$, preventing the propagation of damaged DNA that leads to apoptosis. The temporary decrease of p53 at 3 days after arteriotomy is thus in agreement with the decrease of other DNA repair-related genes and could be related to the activation of cell proliferation stimulated by arteriotomy (Fig. 3).

CAT and SOD are antioxidant enzymes contributing to the reduction of ROS [37]. The level of superoxide anions has been demonstrated to increase in the arteries 3 days after angioplasty [38]. The decrease of CAT at 3 days after arteriotomy (Fig. 3) can be responsible for an increase of $\mathrm{H}_{2} \mathrm{O}_{2}$ in cells in the vascular wall submitted to arteriotomy and thus contribute to the accumulation of DNA oxidative damage as well as to cell proliferation, since $\mathrm{H}_{2} \mathrm{O}_{2}$ is endowed also with a potent mitogen effect [39].

\section{Arteriotomy affects the time-dependent expression of a panel of DNA repair-related genes:}

In mammalian cells, a network of biochemical pathways exists to maintain the functional and structural integrities of the genome.

The decrease of the majority of DNA repair-related genes we analysed indicates at least a partially compromised DNA repair machinery in the acute phase following arteriotomy. To our knowledge, this is the first study that describes in detail the expression profile of a dataset of genes involved in DNA repair after vascular injury. Nonetheless, it should be underlined that this subgroup of genes is only representative of a complex mechanism that is based on the contribution of a number of factors, regulated at different levels.

A previous study demonstrated the effectiveness of local delivery of RAD50, a gene playing a key role in recognizing and signaling DSBs, in reducing intimal hyperplasia in a model of porcine coronary stent deployment [40]. These data are of interest as they indicate that an overexpression of proteins involved in DNA repair could be helpful in regression of restenosis. 


\section{CONCLUSIONS}

To our knowledge, this is the first time-dependent expression analysis of an extended panel of DNA repair-related genes, together with the immunohistochemical analysis of DNA damage markers and the determination of cell proliferation and apoptosis indexes, conducted in parallel in the same model of surgical vascular injury.

Persistent DNA damage may negatively affect a variety of cellular processes in vascular stenosis induced by surgical injury, including cell survival and proliferation. An antioxidant therapy could be helpful in reducing harmful effects of oxidative stress on the vascular wall submitted to injury, as demonstrated by studies conducted in patients, in animal models and in vitro [41-46]

Our findings are descriptive and further analyses are currently in progress to dissect their underlying mechanisms. Nonetheless, these results provide information in the molecular events triggered by vascular surgical injury and suggest that molecules involved in DNA damage and repair could represent a good target for reduction of restenosis, and that the best therapeutic window for modulation of these molecules should be carefully considered on the basis of their expression profiles and in the context of the vascular injury applied. 


\section{ACKNOWLEDGEMENTS}

This work has been partially funded by SHRO grant to U.G.

We are grateful to Ms. Maria Rosaria Cipollaro for skilful assistance and to Dr. Monica Mattia for excellent care of animal welfare. 


\section{LEGENDS}

Figure 1: Immunohistochemical analysis of the proliferation index, the apoptosis index and the DNA oxidative damage index at 3 and 7 days after carotid arteriotomy and in carotids from uninjured rats.

Upper panel: percentage in the tunicae media and intima of cells positive to BrdU and TUNEL assays and to 8-oxo-dG marker.

Lower panel: A, B, C: Representative immunohistochemical staining of BrdU in injured rat carotids at 3 (B) and 7 (C) days after arteriotomy and in uninjured carotids (A). Hematoxylin nuclei counterstaining. Subparts represent 100x magnification of the area enclosed in the black perimeter (40x magnification). D, E, F: Representative immunohistochemical staining of 8-oxo-dG DNA oxidative damage in injured rat carotids at $3(\mathbf{E})$ and $7(\mathbf{F})$ days after arteriotomy and in uninjured carotids (D). Hoechst 33258 nuclei counterstaining (40x magnification). G, H, I: Representative immunohistochemical detection of apoptotic cells through the TUNEL assay in injured rat carotids at $3(\mathbf{H})$ and 7 (I) days after arteriotomy and in uninjured carotids (G). Hoechst 33258 nuclei counterstaining (40x magnification). White arrows indicate representative cells positive to 8-oxodG (E) and to TUNEL assay (H, I). (A: adventitia; M: Media; L: Lumen)

Figure 2: Immunohistochemical analysis of the DNA damage marker phospho-H2A.X at 4 hrs (B), 3 (C) and 7 days (D) after carotid arteriotomy and in uninjured carotids (A). Hematoxylin nuclei counterstaining. Subparts represent 100x magnification of the area enclosed in the black perimeter (40x magnification). Representative positive cells are shown in the adventitia (B), in the media (C) and in the neointima (D).

Figure 3: Western Blot analysis of proteins p53, Mn-SOD and catalase at 3 and 7 days after arteriotomy and in carotids from uninjured rats. $\S: p=0.04 ; *: p=0.02$.

A: densitometric analysis of protein bands showed in B. All measurements were normalized with respect to endogenous $\alpha$-tubulin levels. B: representative Western Blot analysis of proteins $\mathrm{Mn}$ SOD, CAT and p53 in carotids harvested at 3 and 7 days after arteriotomy and in carotids from uninjured rats.

Figure 4: RT-PCR analysis of the expression of mRNAs coding for molecules involved in DNA repair pathways BER, MER, NER and DSBs at 3 and 7 days after arteriotomy and in carotids from uninjured rats. All measurements were normalized with respect to endogenous GAPDH levels. The values are expressed in arbitrary units as relative changes over the normalized uninjured control. Data are presented as the mean \pm SEM. Ogg1 in BER: ${ }^{*} \mathrm{p}=0.04$ versus uninjured carotids; Mre11a and Xrcc4 in DSB: ${ }^{*} p=0.04$ and $\$ p=0.01$ versus uninjured carotids, respectively. Rad23a and Slk in NER: ${ }^{*} \mathrm{p}=0.04$ and $\# \mathrm{p}=0.01$ versus uninjured carotids, respectively. Prkdc in MER: ${ }^{*} \mathrm{p}=0.04$ versus uninjured carotids.

\section{TABLES}

Table I: Summary of RT-PCR primer sequences, position, annealing temperature, PCR product length and function of the DNA repair pathways target genes. 


\section{REFERENCES}

1. Kastrup, A., Groschel, K. (2007) Carotid endarterectomy versus carotid stenting: an updated review of randomized trials and subgroup analyses. Acta Chir Belg 107, 119-128

2. Lal, B.K. (2007) Recurrent carotid stenosis after CEA and CAS: diagnosis and management. Semin Vasc Surg 20, 259-266

3. Khurana, R., Zhuang, Z., Bhardwaj, S., Murakami, M., De Muinck, E., Yla-Herttuala, S., Ferrara, N., Martin, J.F., Zachary, I., Simons, M. (2004) Angiogenesis-dependent and independent phases of intimal hyperplasia. Circulation 110, 2436-2443

4. Christen, T., Verin, V., Bochaton-Piallat, M., Popowski, Y., Ramaekers, F., Debruyne, P., Camenzind, E., van Eys, G., Gabbiani, G. (2001) Mechanisms of neointima formation and remodeling in the porcine coronary artery. Circulation 103, 882-888

5. Hordijk, P.L. (2006) Regulation of NADPH oxidases: the role of Rac proteins. Circ Res 98, 453-462

6. Yeh, L.H., Park, Y.J., Hansalia, R.J., Ahmed, I.S., Deshpande, S.S., Goldschmidt-Clermont, P.J., Irani, K., Alevriadou, B.R. (1999) Shear-induced tyrosine phosphorylation in endothelial cells requires Rac1-dependent production of ROS. Am J Physiol 276, C838-847

7. Hitomi, H., Kiyomoto, H., Nishiyama, A. (2007) Angiotensin II and oxidative stress. Curr Opin Cardiol 22, 311-315

8. Liu, H., Colavitti, R., Rovira, II, Finkel, T. (2005) Redox-dependent transcriptional regulation. Circ Res 97, 967-974

9. Clempus, R.E., Griendling, K.K. (2006) Reactive oxygen species signaling in vascular smooth muscle cells. Cardiovasc Res 71, 216-225

10. Irani, K. (2000) Oxidant signaling in vascular cell growth, death, and survival : a review of the roles of reactive oxygen species in smooth muscle and endothelial cell mitogenic and apoptotic signaling. Circ Res 87, 179-183

11. Madamanchi, N.R., Vendrov, A., Runge, M.S. (2005) Oxidative stress and vascular disease. Arterioscler Thromb Vasc Biol 25, 29-38

12. Forte, A., Di Micco, G., Galderisi, U., Guarino, F.M., Cipollaro, M., De Feo, M., Gregorio, R., Bianco, M.R., Vollono, C., Esposito, F., Berrino, L., Angelini, F., Renzulli, A., Cotrufo, M., Rossi, F., Cascino, A. (2001) Molecular analysis of arterial stenosis in rat carotids. J Cell Physiol 186, 307-313

13. Forte, A., Finicelli, M., De Luca, P., Quarto, C., Onorati, F., Sante, P., Renzulli, A., Galderisi, U., Berrino, L., De Feo, M., Rossi, F., Cotrufo, M., Cascino, A., Cipollaro, M. (2008) Expression profiles in surgically-induced carotid stenosis: a combined transcriptomic and proteomic investigation. J Cell Mol Med 12, 1956-1973

14. Neeley, W.L., Essigmann, J.M. (2006) Mechanisms of formation, genotoxicity, and mutation of guanine oxidation products. Chem Res Toxicol 19, 491-505

15. Kinner, A., Wu, W., Staudt, C., Iliakis, G. (2008) Gamma-H2AX in recognition and signaling of DNA double-strand breaks in the context of chromatin. Nucleic Acids Res 36, 5678-5694

16. Kuo, L.J., Yang, L.X. (2008) Gamma-H2AX - a novel biomarker for DNA double-strand breaks. In Vivo 22, 305-309

17. Zhang, C., Yang, J., Jennings, L.K. (2004) Attenuation of neointima formation through the inhibition of DNA repair enzyme PARP-1 in balloon-injured rat carotid artery. Am J Physiol Heart Circ Physiol 287, H659-666

18. Okamoto, E., Couse, T., De Leon, H., Vinten-Johansen, J., Goodman, R.B., Scott, N.A., Wilcox, J.N. (2001) Perivascular inflammation after balloon angioplasty of porcine coronary arteries. Circulation 104, 2228-2235

19. Mahmoudi, M., Gorenne, I., Mercer, J., Figg, N., Littlewood, T., Bennett, M. (2008) Statins use a novel Nijmegen breakage syndrome-1-dependent pathway to accelerate DNA repair in vascular smooth muscle cells. Circ Res 103, 717-725 
20. Martinet, W., Knaapen, M.W., De Meyer, G.R., Herman, A.G., Kockx, M.M. (2002) Elevated levels of oxidative DNA damage and DNA repair enzymes in human atherosclerotic plaques. Circulation 106, 927-932

21. Pollman, M.J., Yamada, T., Horiuchi, M., Gibbons, G.H. (1996) Vasoactive substances regulate vascular smooth muscle cell apoptosis. Countervailing influences of nitric oxide and angiotensin II. Circ Res 79, 748-756

22. Bennett, M.R. (1999) Apoptosis of vascular smooth muscle cells in vascular remodelling and atherosclerotic plaque rupture. Cardiovasc Res 41, 361-368

23. Rivard, A., Luo, Z., Perlman, H., Fabre, J.E., Nguyen, T., Maillard, L., Walsh, K. (1999) Early cell loss after angioplasty results in a disproportionate decrease in percutaneous gene transfer to the vessel wall. Hum Gene Ther 10, 711-721

24. Perlman, H., Maillard, L., Krasinski, K., Walsh, K. (1997) Evidence for the rapid onset of apoptosis in medial smooth muscle cells after balloon injury. Circulation 95, 981-987

25. Bochaton-Piallat, M.L., Gabbiani, F., Redard, M., Desmouliere, A., Gabbiani, G. (1995) Apoptosis participates in cellularity regulation during rat aortic intimal thickening. Am J Pathol 146, 1059-1064

26. Malik, N., Francis, S.E., Holt, C.M., Gunn, J., Thomas, G.L., Shepherd, L., Chamberlain, J., Newman, C.M., Cumberland, D.C., Crossman, D.C. (1998) Apoptosis and cell proliferation after porcine coronary angioplasty. Circulation 98, 1657-1665

27. Walsh, K., Isner, J.M. (2000) Apoptosis in inflammatory-fibroproliferative disorders of the vessel wall. Cardiovasc Res 45, 756-765

28. Mercer, J., Figg, N., Stoneman, V., Braganza, D., Bennett, M.R. (2005) Endogenous p53 protects vascular smooth muscle cells from apoptosis and reduces atherosclerosis in ApoE knockout mice. Circ Res 96, 667-674

29. Oka, S., Ohno, M., Tsuchimoto, D., Sakumi, K., Furuichi, M., Nakabeppu, Y. (2008) Two distinct pathways of cell death triggered by oxidative damage to nuclear and mitochondrial DNAs. EMBO J 27, 421-432

30. Mukherjee, B., Kessinger, C., Kobayashi, J., Chen, B.P., Chen, D.J., Chatterjee, A., Burma, S. (2006) DNA-PK phosphorylates histone H2AX during apoptotic DNA fragmentation in mammalian cells. DNA Repair (Amst) 5, 575-590

31. Solier, S., Pommier, Y. (2009) The apoptotic ring: a novel entity with phosphorylated histones H2AX and H2B and activated DNA damage response kinases. Cell Cycle 8, 18531859

32. Scheinman, M., Ascher, E., Levi, G.S., Hingorani, A., Shirazian, D., Seth, P. (1999) p53 gene transfer to the injured rat carotid artery decreases neointimal formation. J Vasc Surg 29, 360-369

33. George, S.J., Angelini, G.D., Capogrossi, M.C., Baker, A.H. (2001) Wild-type p53 gene transfer inhibits neointima formation in human saphenous vein by modulation of smooth muscle cell migration and induction of apoptosis. Gene Ther 8, 668-676

34. Matsushita, H., Morishita, R., Aoki, M., Tomita, N., Taniyama, Y., Nakagami, H., Shimozato, T., Higaki, J., Kaneda, Y., Ogihara, T. (2000) Transfection of antisense p53 tumor suppressor gene oligodeoxynucleotides into rat carotid artery results in abnormal growth of vascular smooth muscle cells. Circulation 101, 1447-1452

35. Linke, S.P., Sengupta, S., Khabie, N., Jeffries, B.A., Buchhop, S., Miska, S., Henning, W., Pedeux, R., Wang, X.W., Hofseth, L.J., Yang, Q., Garfield, S.H., Sturzbecher, H.W., Harris, C.C. (2003) p53 interacts with hRAD51 and hRAD54, and directly modulates homologous recombination. Cancer Res 63, 2596-2605

36. Bakalkin, G., Yakovleva, T., Selivanova, G., Magnusson, K.P., Szekely, L., Kiseleva, E., Klein, G., Terenius, L., Wiman, K.G. (1994) p53 binds single-stranded DNA ends and catalyzes DNA renaturation and strand transfer. Proc Natl Acad Sci U S A 91, 413-417

37. Szocs, K., Lassegue, B., Sorescu, D., Hilenski, L.L., Valppu, L., Couse, T.L., Wilcox, J.N., Quinn, M.T., Lambeth, J.D., Griendling, K.K. (2002) Upregulation of Nox-based NAD(P)H oxidases in restenosis after carotid injury. Arterioscler Thromb Vasc Biol 22, 21-27 
38. Durand, E., Al Haj Zen, A., Addad, F., Brasselet, C., Caligiuri, G., Vinchon, F., Lemarchand, P., Desnos, M., Bruneval, P., Lafont, A. (2005) Adenovirus-mediated gene transfer of superoxide dismutase and catalase decreases restenosis after balloon angioplasty. J Vasc Res 42, 255-265

39. Herbert, J.M., Bono, F., Savi, P. (1996) The mitogenic effect of $\mathrm{H} 2 \mathrm{O} 2$ for vascular smooth muscle cells is mediated by an increase of the affinity of basic fibroblast growth factor for its receptor. FEBS Lett 395, 43-47

40. Ahn, Y.K., Kook, H., Jeong, M.H., Ahn, K.Y., Cho, J.G., Park, J.C., Kang, J.C., Kim, K.K. (2004) Local RAD50 gene delivery induces regression of preformed porcine coronary instent neointimal hyperplasia. J Gene Med 6, 93-104

41. Kaminnyi, A.I., Shuvalova Iu, A., Lankin, V.Z., Piksina, G.F., Shirokov, R.O., Samko, A.N., Kukharchuk, V.V. (2009) [Antioxidant status and restenosis after stenting of coronary arteries]. Kardiologiia 49, 14-18

42. Watt, J., Wadsworth, R., Kennedy, S., Oldroyd, K.G. (2008) Pro-healing drug-eluting stents: a role for antioxidants? Clin Sci (Lond) 114, 265-273

43. Kanellakis, P., Nestel, P., Bobik, A. (2004) Angioplasty-induced superoxide anions and neointimal hyperplasia in the rabbit carotid artery: suppression by the isoflavone transtetrahydrodaidzein. Atherosclerosis 176, 63-72

44. Kanellakis, P., Pomilio, G., Walker, C., Husband, A., Huang, J.L., Nestel, P., Agrotis, A., Bobik, A. (2009) A novel antioxidant 3,7-dihydroxy-isoflav-3-ene (DHIF) inhibits neointimal hyperplasia after vessel injury attenuating reactive oxygen species and nuclear factor-kappaB signaling. Atherosclerosis 204, 66-72

45. Zou, J., Huang, Y., Cao, K., Yang, G., Yin, H., Len, J., Hsieh, T.C., Wu, J.M. (2000) Effect of resveratrol on intimal hyperplasia after endothelial denudation in an experimental rabbit model. Life Sci 68, 153-163

46. Lin, S.J., Yang, T.H., Chen, Y.H., Chen, J.W., Kwok, C.F., Shiao, M.S., Chen, Y.L. (2002) Effects of Ginkgo biloba extract on the proliferation of vascular smooth muscle cells in vitro and on intimal thickening and interleukin-1beta expression after balloon injury in cholesterol-fed rabbits in vivo. J Cell Biochem 85, 572-582 


\begin{tabular}{|c|c|c|c|c|c|c|}
\hline DNA REPAIR PATHWAY & GENE & $\begin{array}{l}\text { PRIMER } \\
\text { POSITION }\end{array}$ & PRIMER SEQUENCE & $\begin{array}{c}\text { ANNEALING } \\
\mathrm{T}\left({ }^{\circ} \mathrm{C}\right)\end{array}$ & \begin{tabular}{|c|} 
PCR \\
PRODUCT \\
LENGHT \\
(bp)
\end{tabular} & GENE FUNCTION \\
\hline \multirow{3}{*}{$\begin{array}{c}\text { DSB } \\
\text { (double strand break) }\end{array}$} & Brca2 & $\begin{array}{l}2088 \\
2253 \\
\end{array}$ & $\begin{array}{l}\text { 5'-GCC ATC TTT GTC CTT GAC CAA-3' } \\
\text { 5'-TGG CAA GCA CGA CAG AAA GTC-3' }\end{array}$ & 56 & 166 & DNA and protein binding \\
\hline & Mre11A & $\begin{array}{l}380 \\
487\end{array}$ & $\begin{array}{l}\text { 5'-GTA TCC ACG GCA ACC ATG ATG-3' } \\
\text { 5'-CCA CAG ACA TTG ACC GTC CAA-3' }\end{array}$ & 60 & 108 & $\begin{array}{c}\text { Endonuclease, exonuclease, } \\
\text { hydrolase activity }\end{array}$ \\
\hline & Xrcc4 & $\begin{array}{l}448 \\
550\end{array}$ & $\begin{array}{l}\text { 5'-AAA ACG AGC ACC TGC AGA AGG-3' } \\
\text { 5'-GCC TCC AAG GCT TCT TTG TCA-3' }\end{array}$ & 59 & 103 & DNA and protein binding \\
\hline \multirow{4}{*}{$\begin{array}{c}\text { MER } \\
\text { (mismatch excision } \\
\text { repair) }\end{array}$} & MIh1 & $\begin{array}{c}892 \\
1008\end{array}$ & $\begin{array}{l}\text { 5'-ATC AGT CCC CAG AAC GTG GAT-3' } \\
\text { 5'-GCC CAA TAG CTT GCT CTC GAT-3' }\end{array}$ & 59 & 117 & ATP and protein binding \\
\hline & Prkdc & $\begin{array}{l}4025 \\
4166 \\
\end{array}$ & $\begin{array}{l}\text { 5'-TTA CCA CAA CCC TGC TCG TCA-3' } \\
\text { 5'-ACC TGG ACG TCG CCA ATA TTG-3' }\end{array}$ & 58 & 142 & $\begin{array}{l}\text { DNA-dependent protein } \\
\text { kinase and protein binding }\end{array}$ \\
\hline & \multirow{2}{*}{ Pold3 } & 1159 & 5'-ACC TCC TGA TCC TGT GCC AAA-3' & \multirow{2}{*}{58} & & \multirow{2}{*}{ Protein binding } \\
\hline & & 1281 & 5'-ACC ATG CAG CCT TCT TCA TCC-3' & & & \\
\hline \multirow{3}{*}{$\begin{array}{c}\text { BER } \\
\text { (base excision repair) }\end{array}$} & Mutyh & $\begin{array}{l}334 \\
447\end{array}$ & $\begin{array}{l}\text { 5'-TTG GAC AGG AGA GCC TAT GCA-3' } \\
\text { 5'-TTG TAG CGT TGG CCA CTT CTG-3' }\end{array}$ & 60 & 114 & DNA glycosylase \\
\hline & Ogg1 & $\begin{array}{l}435 \\
548\end{array}$ & $\begin{array}{l}\text { 5'-ACA AGA CCC CAC TGA ATG CCT-3' } \\
\text { 5'-TGA ACG AGT CGA GGT CCA AAG-3' }\end{array}$ & 59 & 114 & DNA glycosylase \\
\hline & Parp1 & $\begin{array}{l}1319 \\
1429\end{array}$ & $\begin{array}{l}\text { 5'-GCT GAC AGG ATC TGC CAA CAA-3' } \\
\text { 5'-CAC ACG ACT CGA ACA TTG GCT-3' }\end{array}$ & 59 & 111 & DNA binding \\
\hline \multirow{4}{*}{$\begin{array}{c}\text { NER } \\
\text { (nucleotide excision } \\
\text { repair) }\end{array}$} & Nthl1 & $\begin{array}{l}257 \\
358\end{array}$ & $\begin{array}{l}\text { 5'-TGA AGA TGC TGA ACC CCT CAA-3' } \\
\text { 5'-ACA GGT GGC TCC TTC TTG CTT-3' }\end{array}$ & 60 & 102 & DNA glycosylase \\
\hline & $\operatorname{Rad} 23 A$ & $\begin{array}{l}1217 \\
1325\end{array}$ & $\begin{array}{l}\text { 5'-TTA TCT CCA TTG GAG TGG CCC-3' } \\
\text { 5'-TGT TAC CCC TTT TCC AGG CTG-3' }\end{array}$ & 61 & 109 & DNA and protein binding \\
\hline & \multirow{2}{*}{ SIk } & 1043 & 5'-AAT TGA TTG CTG AGG CGA AGG-3' & \multirow{2}{*}{58} & \multirow{2}{*}{104} & \multirow{2}{*}{ Nuclease activity } \\
\hline & & 1146 & 5'-ATT CGC AGG TAT TGG CAG AGC-3' & & & \\
\hline
\end{tabular}

Licenced copy. Copying is not permitted, except with prior permission and as allowed by law. (C) 2009 The Authors Journal compilation (c) 2009 Portland Press Limited 

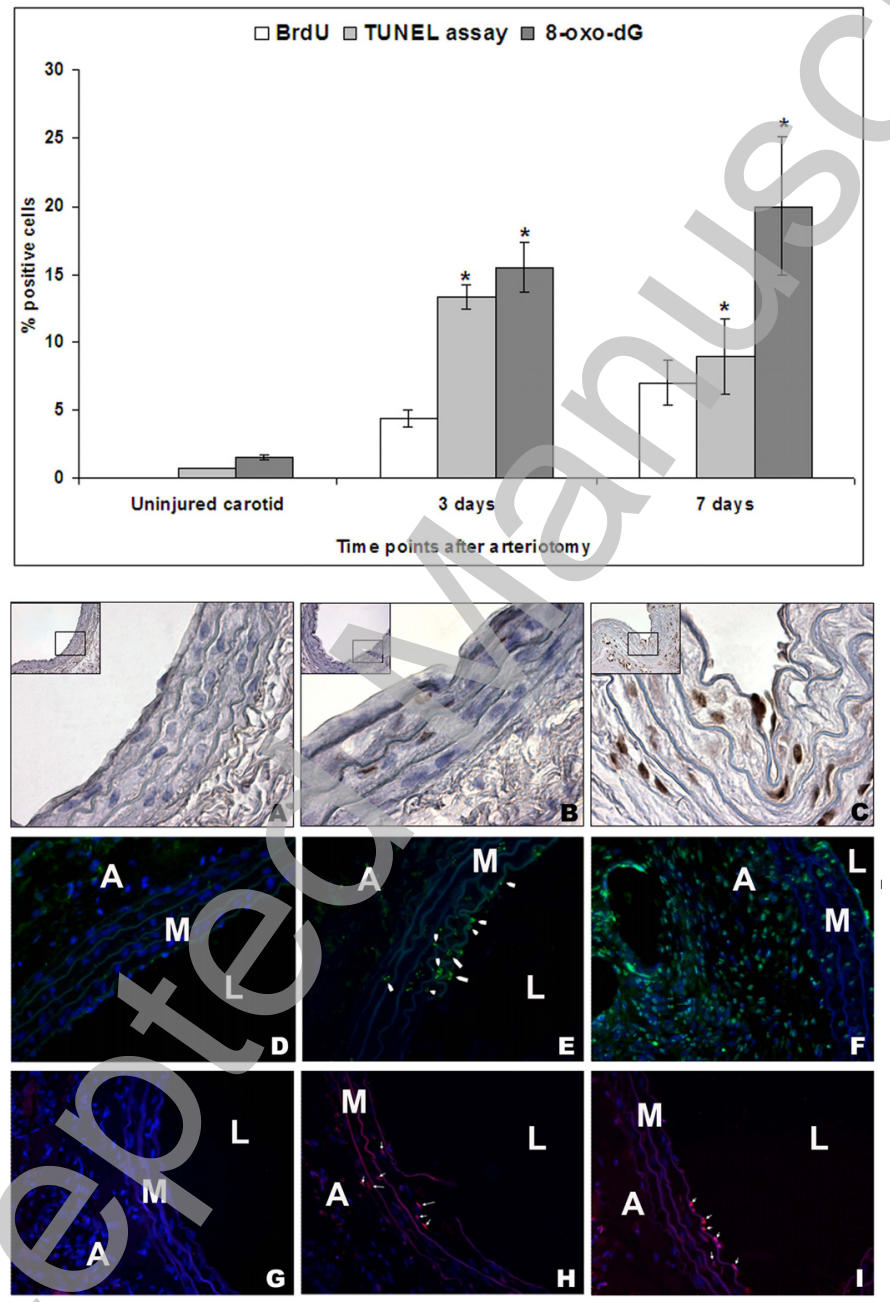

Licenced copy. Copying is not permitted, except with prior permission and as allowed by law. (C) 2009 The Authors Journal compilation (c) 2009 Portland Press Limited 


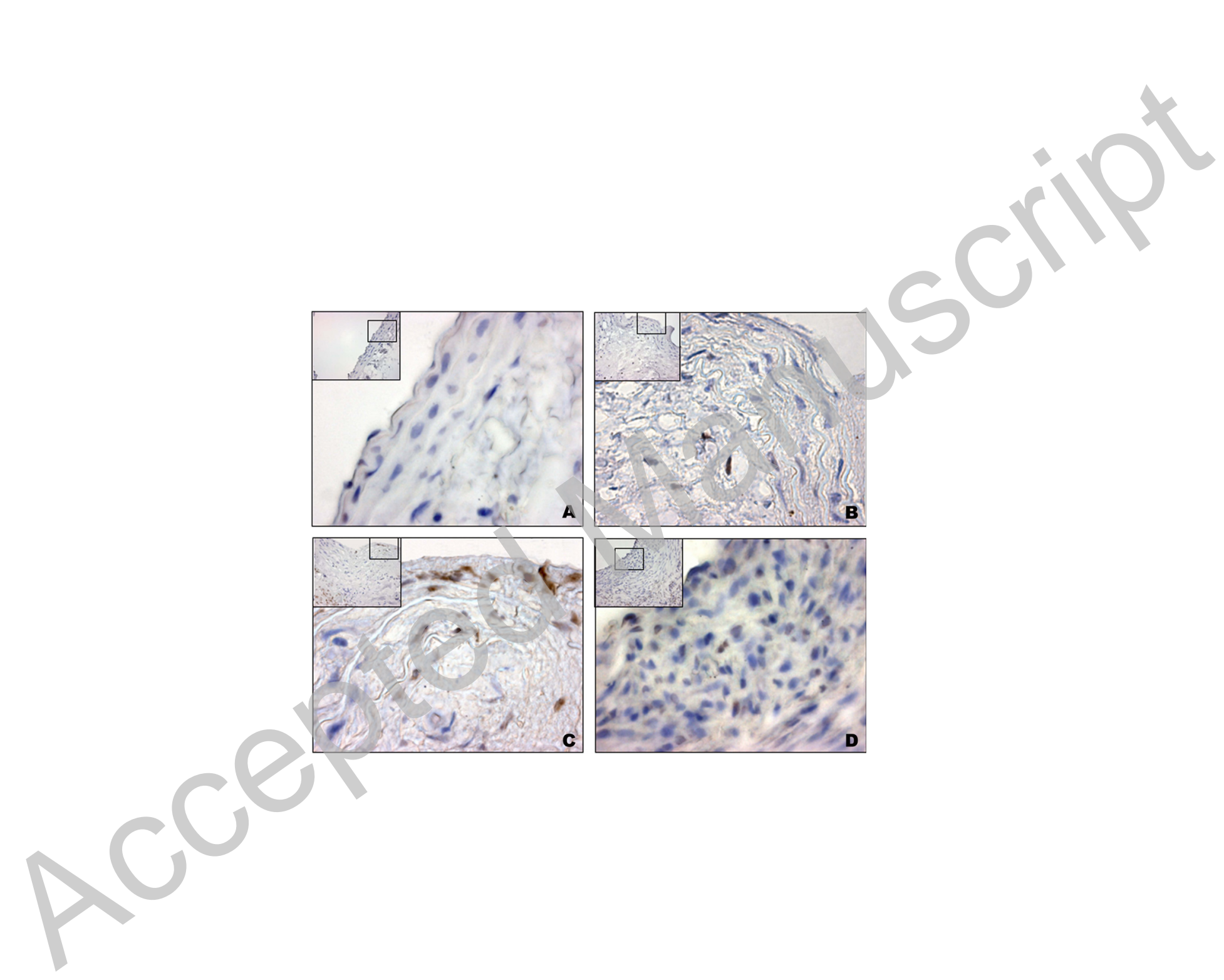




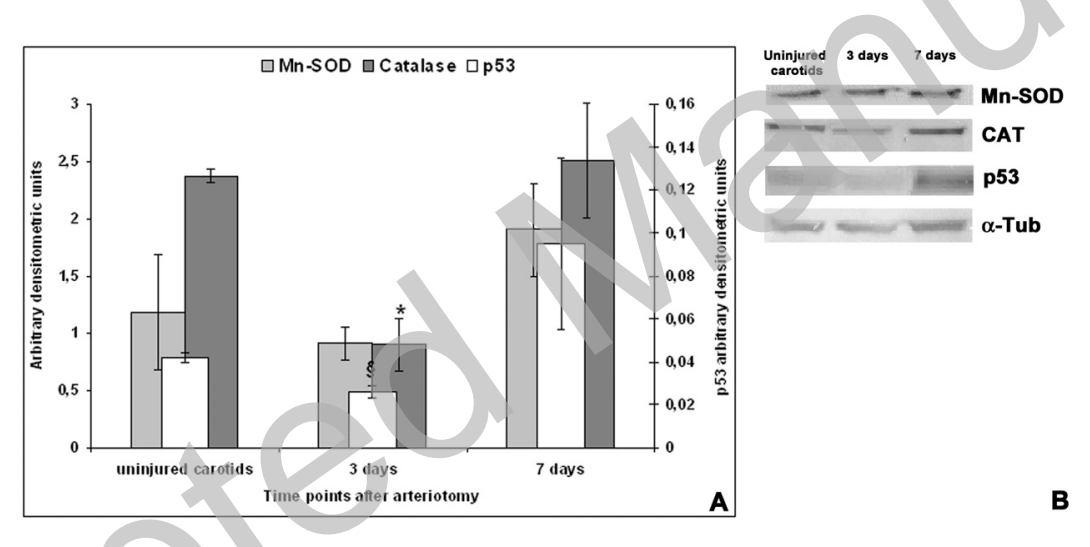

Licenced copy. Copying is not permitted, except with prior permission and as allowed by law. (C) 2009 The Authors Journal compilation @ 2009 Portland Press Limited 

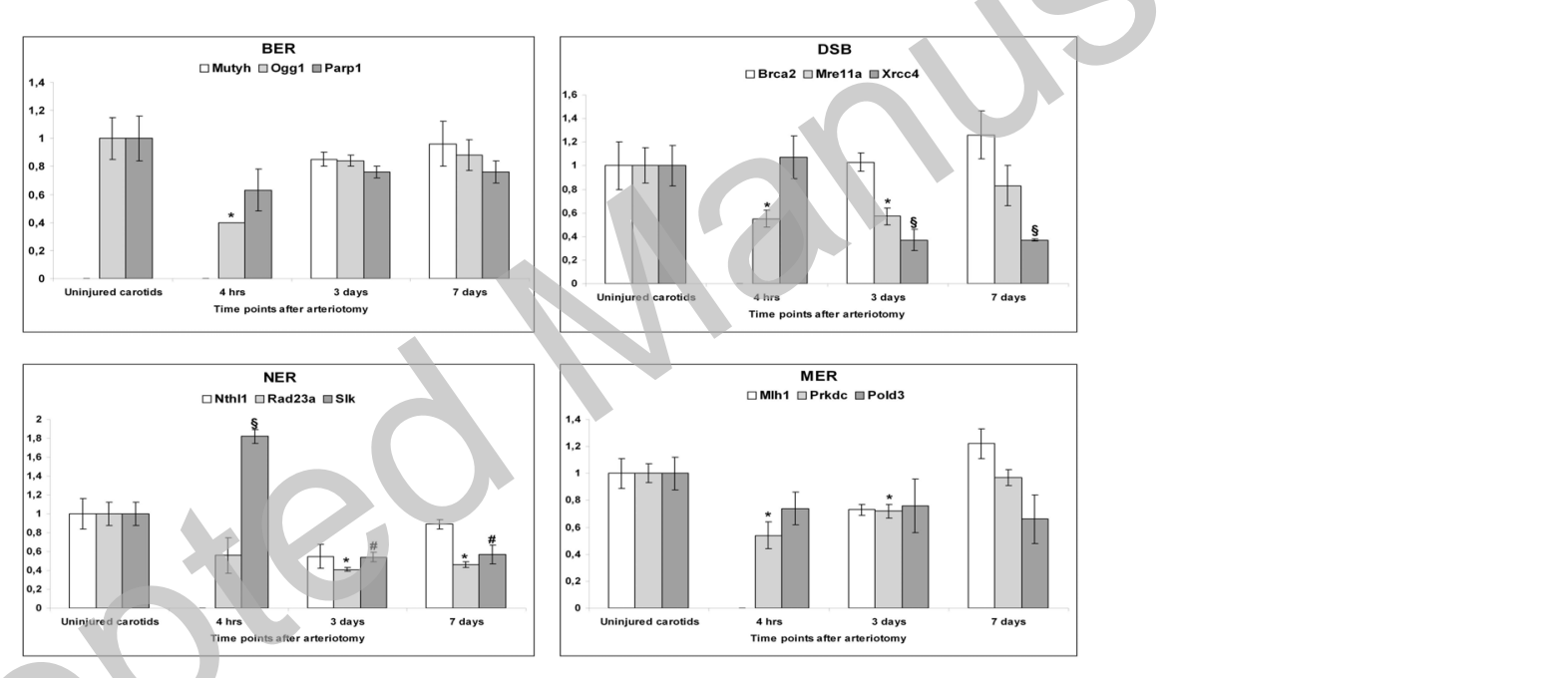

Licenced copy. Copying is not permitted, except with prior permission and as allowed by law. (C) 2009 The Authors Journal compilation @ 2009 Portland Press Limited 